\title{
Gendered politics in rural roads: gender mainstreaming in Tanzania"s transport sector
}

\section{Godfrey Mulongo PhD}

Director, Monitoring and Evaluation, Value Plus Consultants Ltd, Nairobi, Kenya (corresponding author: mulongoe@gmail.com)

(Orcid:0000-0001-8726-5404)

Gina Porter PhD

Professor, Department of Anthropology, Durham University, Durham, UK
Amleset Tewodros MA

Immediate Africa Region Head of Programmes, HelpAge International, Dar es Salaam, Tanzania

This paper explores the impacts of gender mainstreaming initiatives in Tanzania's transport sector on the everyday reality of rural women's lives, including those facing multiple forms of discrimination. Using qualitative methods, including co-investigation with community members, data were triangulated from diverse sources: vulnerable women and other residents in two Tanzanian districts, road contractors, professionals engaged in supporting the country's transport programmes and staff in donor agencies. The results indicate that progress in mainstreaming has been slow. Despite government directives, few women have benefitted from employment in road construction except through two national programmes: the Village Travel and Transport Programme and the Tanzania Social Action Fund. However, most women, particularly those disadvantaged, derive benefit from road improvement, even if only as pedestrians or wheelchair users taking advantage of a smoother surface, or better travel security when vegetation is cut back. For women with the funds and independence to access the expanded transport services that tend to follow road improvements, there can be significant benefits - faster travel, improved access to farms and markets and sometimes lower transport costs. Nevertheless, women's constrained resources and prevailing cultural mores continue to militate against them directly operating transport, whether for personal or business use.

\section{Introduction}

Over the last three decades, a substantial body of evidence on women's transport and mobility constraints and needs in Africa has accumulated (e.g. Fernando and Porter, 2002; MalmbergCalvo, 1994a, 1994b; Porter, 2008, 2011, 2014; Turner et al., 2014; Urasa, 1990). The evidence points to the crucial importance of women's access to mobility and transport, not only for personal empowerment but also for the wider development objectives associated with their access to schools, health services and markets. With multi- and bi-lateral donor support, such evidence has encouraged the promotion of 'gender mainstreaming' policies and programmes in the transport sector across the continent, with implications extending from women's employment to satisfying their needs as users of transport services. Tanzania is no exception: section 8.1 of the National Transport Policy (United Republic of Tanzania, 2011) refers to gender as a crosscutting issue that is essential for women's empowerment, equal opportunities and social inclusion such that gender mainstreaming is to be promoted in services, operations and infrastructure.

Yet even a fleeting journey into rural Africa today will commonly reveal a transport landscape that is still dominated by male-driven vehicles and (a good proportion of) male passengers hurtling along (literally man-made) major and minor roads, while women and their children trudge along poorly defined road margins, dodging traffic and balancing heavy loads. Automobility - along with the construction of the roads on which it is practised - remains, in essence, a masculine project. Why should this still be the case, given the commitment to gender equality recited in so many hundreds of national policy documents?

This paper examines the place of women in the rural transport sector - as travellers, road workers and transport professionals with particular reference to Tanzania. Data were triangulated from diverse sources: poor women and other rural residents in two Tanzanian districts, professionals (male and female) engaged in supporting the country's transport programmes at local and national levels, and relevant staff in donor agencies that have been significant funders of the country's transport programmes. Using a qualitative research methodology, the impact of gender mainstreaming initiatives in Tanzania's rural transport sector was traced and the impact of these on the everyday reality of people's lives was assessed. The co-investigation approach adopted - whereby community members were trained as co-researchers - aided the process.

Intricately interlinked through the stories gathered in this research are references - sometime oblique, sometimes direct - to the interplay of power relations that shape transport-related debates, planning and engineering practice, onand off-site employment decisions and associated travel experiences. There is an interplay between genders as they operate at different scales and across scales: male jostling for advantage occurs in village meetings, contractors' compounds and local and central government offices, while women mostly lose out. 
This research showed that vulnerable women - those perhaps particularly disadvantaged by orphanhood, disability or widowhood - face even greater barriers in the contemporary transport landscape. The paper first presents relevant background literature and details of the methodology employed. This is followed by an examination of the gendered implications of road interventions, including employment practices in road construction. The concluding section reviews the interplay of power that shapes these outcomes and offers suggestions for future policy and practice.

\subsection{Gender roles and the transport sector: a review of key issues}

Roads are not only a means by which services and goods can be accessed by rural people; they also provide potential employment niches, through transport service operations, infrastructure construction and maintenance work. This section reviews relevant key literature with specific reference to gender issues.

Gender shapes mobility and access to transport services - who goes where, when, by what means. Women's prevailing triple roles in rural Africa (entailing productive, reproductive and community maintenance work) impact substantially on their travel opportunities and practices because they affect their time availability, financial resources and the nature of travel. Men are usually better financially resourced and have fewer time/socio-cultural constraints on their travel (Fernando and Porter, 2002; Porter, 2008). There is, in particular, widespread (male) association of female mobility with vulnerability and promiscuity and associated (female) fear of harassment on journeys (as Haram (2004) noted with reference to traditional moral codes among rural Meru in northern Tanzania). Thus, while infrastructure and transport services commonly present significant, interlinked constraints on rural people's movement in general (due to poor availability, low reliability, poor safety and high cost), they tend to have a greater impact on women. Even so, it is important to point out that not all women suffer transport constraints to the same degree (given significant variations in socio-economic status, health status, age etc.). Moreover, other vulnerable groups may suffer mobility disadvantages, notably people with disabilities, older people and children, as noted in section 8.3 of the $2011 \mathrm{draft}$ National Transport Policy (United Republic of Tanzania, 2011) (see also Porter et al. (2013b) with reference to older people in the Kibaha district).

In Tanzania, issues around women's transport burden and time poverty were first highlighted years ago in studies conducted during the Makete Integrated Rural Transport Project, which ran from 1985 to 1996 (Barwell and Malmberg-Calvo, 1986, 1988a, 1988b; Jennings, 1992; Malmberg-Calvo, 1994a). Bryceson and Howe (1993) calculated that Makete men contributed only about $25 \%$ of the time that women contributed to transport and were performing only approximately $11 \%$ of the load-carrying effort. Women still appear to play a major role in pedestrian load carrying across all regions of Tanzania although there is an absence of recent data to confirm this perception. The socially defined roles of men and women, and women's labour burden, appear to have changed little in Tanzania since then (Ellis, 2007; Green, 2010; Ishengoma, 2004; Mwankusye, 2002; Ponte, 2002). Indeed, Mbilinyi and Shechambo (2015) argue that conditions for Tanzanian women have deteriorated over a long period following structural adjustment in the 1980s: while privatisation and liberalisation of social and economic services and privatisation of land tenure affected both men and women, women have suffered more through their vulnerability to land dispossession because of patriarchal property and inheritance systems, such that many women have had to seek precarious work as casual labourers in agriculture and other sectors.

The poor access of women and girls to road transport services has major implications for development trajectories: it impacts on female education, health, livelihoods and on intergenerational transfers of poverty (Babinard and Roberts, 2006; Porter, 2008; Porter et al., 2017). There are both education- and health-focused studies in Tanzania that indicate significant female disadvantage in accessing services because of transport constraints. In the health sector, where such evidence is now particularly substantial, the transportMYpatient programme of the Comprehensive Community Based Rehabilitation in Tanzania Disability Hospital was introduced in 2009 to address transport costs because of the transport issues faced by women seeking treatment for obstetric fistula (see Fiander et al., 2013).

Transport services often offer an employment niche for the very poorest, including women. For women, this usually involves pedestrian porterage, which can be burdensome and is potentially detrimental to health (Porter et al., 2013a); for men, it may involve porterage, intermediate means of transport operation or motorised transport (as minibus call-boys etc.). The strong connection between male identity and motor-mobility shapes the patterns of transport operation in Tanzania, as across Africa. In rural transport services operations of all types, women have commonly faced significant stigma, whether with reference to cycling or driving a motor vehicle. They are also constrained by inadequate resources to learn to cycle or drive, while the purchase of a private vehicle is usually far beyond their wildest dreams. Thus, in rural areas, it is still rare to see women drivers in charge of either private or commercial vehicles.

It is important to note in this context that the rural transport scene in rural Africa has changed dramatically in recent years with the widespread availability of cheap imported Chinese motorcycles and high demand for motorcycle taxi services (Hine, 2014; Porter, 2014, 2016; Porter et al., 2013a; Starkey, 2011). Tanzania is no exception. Recent data in Tanzania (WHO, 2015) indicate that motorcycles now exceed bicycles on $20 \%$ of roads. So-called boda-boda taxi operations, mostly 
operated by young men (no record of a woman driver was found in the study districts in this work), are frequently used to carry passengers and freight. However, rural motorcycle passenger fares are expensive: a survey in Tanzania conducted by Starkey et al. (2013) revealed rates of 17-34 US cents $/ \mathrm{km}$ compared with rural bus fares of 3.5-4.7 US cents $/ \mathrm{km}$. The expense of travel impacts women more than men: far fewer women than men are able to take advantage of boda-boda as passengers: in Kibaha district, $18 \%$ of older women compared with $31 \%$ of older men $(n=339)$ had used one in the week before the survey in 2012. Their cost limits usage and excludes the poorest in Kibaha (especially given high night-time and rainy season charges; Porter et al., 2013a). However, despite this and current accident rates, boda-boda offer the only door-to-door service in many locations and are now proving a lifeline for both genders in some more remote areas, especially in emergencies.

The transport infrastructure construction sector is another area traditionally dominated by men. While there is growing acceptance of quotas for women road workers in Africa, discrimination against women ranges from lower pay and lack of skills training and promotion opportunities to increased risk of sexual harassment and gender-based violence. Labour-based projects are often focused principally on temporary employment generation for vulnerable groups, but it is still difficult to ensure that women benefit (Mashiri and Mahapa, 2002). In Tanzania, the 2003 Construction Industry Policy stated that at least $25 \%$ of women should benefit from employment in road works and related infrastructure development activities (United Republic of Tanzania, 2003). However, Kabeer (2014) suggest that there have been varying gendered patterns of interest in road work over the years, depending substantially on the absence of profitable alternatives. For example, in the Ruvuma area, where good agricultural opportunities were poor, men ensured they took all the road construction work available, leaving nothing for women, whereas in the Songea district, good tobacco-growing opportunities for men meant that women were more able to access road construction work. In the Matengo district, neither men nor women were reportedly interested in road construction opportunities because of the potential that coffee cultivation offered both sexes. However, for poor, divorced women with children and parents to support, the evidence suggests that road construction has often been the only stable secure form of income.

\section{Methodology}

In this study, qualitative research was conducted in the vicinity of recently completed road construction work in two rural districts of Tanzania - Kilolo district, located in the Iringa region, about $400 \mathrm{~km}$ from the capital Dar es Salaam, and Kibaha district, only about $80 \mathrm{~km}$ from the capital and more closely linked to it by a major trunk route. In both districts, the majority of roads are unsurfaced, but conditions are particularly challenging in the remote rural Kilolo district where the topography is heavily dissected. The authors had conducted earlier mobility-related research in both districts, hence their selection for this study.

Participatory in-depth interviews in the communities encompassed storytelling exercises, photo diaries and focus group discussions with separate groups of women and men.

A co-investigation approach was adopted (Porter, 2014, 2016) whereby two older men and three older women (55-67 years old) from the communities were recruited and trained as active researchers along with 15 supporting research assistants (eight 24-35 years old, all tertiary educated). They subsequently worked together in research teams, led by the peer researchers who conducted the interviews (in Kiswahili) with support from the research assistants and the main project researchers. Peer research of this type is rare, but vital where the perceptions and needs of very marginalised groups are to be adequately understood. Although efforts to recruit peer researchers living with disability were unsuccessful, the five trained peer researchers knew the communities well and were able to locate especially vulnerable people for interview.

Following this initial training phase, a series of 16 focus groups were conducted in each of the two study districts. These focus groups consisted of three with 'ordinary' community women, three with 'ordinary' men, seven with particularly disadvantaged girls and women and three with disadvantaged men. The disadvantaged groups included people with a disability, widows, orphans, older people and those suffering from human immunodeficiency virus/acquired immune deficiency syndrome (HIV/AIDS). Additional in-depth life history interviews took place with disadvantaged women within the communities and with village key informants (village executive officers and chairs, women's group leaders, local road contractors, ward executive officers) and at district offices (with district community development officers, district engineers, planning officers and social development staff). Finally, key informant interviews were conducted in Dar es Salaam with relevant senior ministry staff (at the Prime Minister's office (PO-RALG) and at the Ministry of Health, Community Development, Gender, Women, the Elderly and Children (MHCGWEC)), with the Tanzania Gender Networking Program and with multi-and bi-lateral donor agencies involved in national transport programmes.

\section{Findings}

\subsection{Gendered benefits of road improvement}

When roads are built, transport service expansion tends to follow, and this has clearly occurred in both study districts. It was hoped to be able to make a specific analysis of the impacts of recent nationally instigated transport programmes in the two study districts, but villagers found it difficult to differentiate such programmes from locally generated interventions affecting their communities. Overall, the experience of road improvements was overwhelmingly positive - even women without the funds 
to pay transport fares welcomed the availability of a smooth-surfaced, open road. As women in Kibaha district observed, the clearing of dense vegetation around the road and the increased frequency of road use specifically improves travel safety for women who walk along the road. However, men have mostly benefitted directly through employment as operators in the expanded transport service sector (notably motorcycle taxis in both districts) and, coupled with their higher propensity to travel, ward officers suggested that $75 \%$ of the benefits of road improvements accrue to men.

Many women in both districts referred to their improved access to services (notably health and education) and markets in recent years, especially in the dry season. Despite a lack of community involvement in road planning (discussed later), the improved roads are seen to benefit everyone in the dry season, although in the wet season poor work becomes evident and improved roads sometimes still become intermittently impassable. In the more remote Kilolo district women traders talked of speedier access to markets and farms. The improved roads and expanded motorcycle services are promoting the marketing of perishable goods like bananas, such that women reported much increased profits, especially among those now organising their trade by phone and using Mpesa (a mobile phone-based money transfer system).

Before the road, we used bicycles as mode of transportation. But now the road is good, and we use vehicles and motorcycles... I spend about 2000 TSH [93 US cents] as fare and it is worth it because I was spending about $4 \mathrm{~h}$ on the road before it was constructed. I therefore can access my business premises early and with much ease. This enables me to serve more customers and therefore improving my income and business in general (female general produce trader).

Another business woman observed

We are now able to travel to (Iringa) town and back to buy commodities, even twice a day... Before, we would pay about $50000 \mathrm{TSH}$ [US\$23] to transport our agricultural goods, but now we pay only 30000 TSH [US\$14] because the road is good.

In a few more accessible locations in Kibaha, the arrival of vans has brought reduced transport fares (1500 TSH (70 US cents) compared with 2500 TSH (US\$1.17) for a standard drop on a motorcycle taxi). One widow in Soga reported that her trading takings have consequently increased from 5000-6000 TSH (US\$2-3) per day to 10-20 000 TSH (US\$4-9), enabling her to invest in two savings groups that give her access to loans. However, a shortage of capital still constrains the ability of many women to expand their businesses substantially, especially those in more remote locations. In such more remote locations the high cost of motorcycle taxi fares, especially in the wet season, remains. Distances to hospital and education services thus continue to be an issue, despite better access to transport, because of the high fares. The dangers of motorcycle travel on unpaved, rough roads also increase.
For more marginalised women (orphans, widows, older people, disabled), the benefits of improved road access and expanded, more regular transport mirror those reported by 'ordinary' groups: improved access to health services and more regular supply of medicines at the dispensaries; improved trading opportunities along the roadsides; improved availability of household commodities in the villages; better education because teachers are more willing to come to work in the villages when they can travel from their homes outside; more income if they have young men in the family working as motorcycle taxi drivers. They also noted that more visitors came to the villages. A 40-year-old primary school teacher who is widowed and HIV-infected reflected on some of these diverse benefits.

I yesterday went to the farm and used only half an hour! I used my colleague's motorbike. He has a farm adjacent to mine. So we often contribute fuel, 1000 TSH each... By 2 p.m. we were back to prepare meals for my children and to attend to other duties at home. Saving time enables me as a single mother to spend more time with my children and help them in many other ways such as homework.

For wheelchair-users, road improvements can greatly improve well-being simply by improving the ability to travel within the settlement, as the following statements show.

It was really hard, I used to crawl because the tricycle could not pass through this bad road. The road was very rugged and one could fall off the tricycle. The problem was compounded during the wet season because traction was poor and I had to get someone to push my wheelchair from the rear. [Prompt] Now I am very mobile; I use the tricycle to obtain my essentials from the market and can do petty business (selling nuts, sugar-cane and ubuyu).

It is somehow easy now to do petty business and even carry water from one place to another. I now can ferry my own water for domestic use and don't have to depend on middle men. [Prompt: how much do you save when you carry water yourself?] Often the bucket costs 100 TSH [5 US cents] at the point of sale. But if you buy it [from middle men], it costs 500 TSH [23 US cents]. So, I save up to 400 TSH [19 US cents] (50-year-old female, Kilolo district, disabled since she contracted polio as a child).

Despite such positive impacts from road improvement, one distinct subset of women still fails to benefit - these are women in Kilolo district whose movements are culturally, not physically, constrained. The following discussion among a small group of women gives some indication of the scale of the problem.

There are some husbands who do not like the idea of their wives travelling out... I am a victim of barring. My husband does not let me travel even for purchasing of personal items. 
My husband also doesn't allow me to travel. He chooses to go in my place whenever I want to. I am less informed of happenings out there.

We have no rights, our husbands decide for us. We are threatened with termination of our marriages should we choose to ignore their restrictions. We choose marriage over travel.

A men's group in the district confirmed that such restrictions are often applied, suggesting that this occurs because 'it seems that women are easily tempted compared to men'. Women's potential promiscuity is a common reason presented by men across diverse African societies for not allowing their wives freedom of movement, whatever the availability of transport services (Porter, 2011). A community development officer in the district noted that this cultural practice is common among all communities in the Iringa region.

\subsection{Road construction planning and gendered employment practices}

While road improvements in the study districts are commonly at the top of community wish-lists, community consultation processes with men and women alike are, from the start, often inauspicious. The story recounted in Ruvu Madinla (Kibaha district) is typical: the community was

just startled to find a bulldozer coming to dig without asking where the road is damaged... Nobody was involved. The bulldozer just comes and excavates and that is all... Decisions are made at the city council. You find that you do not even know what the contractor looks like.

This point was echoed in Kilolo district, where village officers again complained of the remoteness of final decisions on road plans: 'The contractors usually come with finalised road maps and directives from higher authorities, so it becomes difficult to offer any sort of advice or assistance'. The district community development officer confirmed this view and its consequences - little commitment to subsequent maintenance because villagers have no sense of ownership of the road.

But even when some community consultation takes place, it is regularly gender-biased. One (female) ward social development officer in Kibaha referred to community identification of areas of road most in need of attention only involving 'older men with good reputation in the ward'! She further observed that although meetings may be composed of $80 \%$ women, $70 \%$ of responses come from men 'because of the cultural practice in our society that empower[s] men to contribute more than women'. When asked about disabled and older people, she suggested that likely mobility constraints will encourage them to 'stay at home and wait for feedback from others'. Meanwhile, the level of gender prejudice that prevails was well exemplified by her male ward officer colleagues who commented that women only tend to exceed men when meetings are called because women are sitting at home, with time to participate, while men were busy as bread-winners for the family! Similarly, in Kilolo, it would appear that women are invited to village consultation meetings but are not expected to input into recommendations, despite the fact that they may be the most affected by decisions: a male village leader stated 'I think they get scared and naturally they are shy; the fact that they have to stand and share their opinion in public terrifies them and makes them pull back'. Yet women do have potentially relevant inputs, with one woman stating 'We would like to see the community more involved in the design and decisions such as where to put road bumps so as to reduce road accidents because we know which areas are highly populated or have many children'.

As the district community development officer observed, with evident frustration, 'at the district council level, despite the fact that the law requires certain gender representation in decision making, this does not happen'. He contrasted the limited capacity of the district to enforce this and the modest scale of district projects compared with national-level projects such as those implemented by TanRoads, citing the case of the Iringato-Idete project for construction of a paved road that involved the community development department to educate the community and prepare it on the gender issues. This was so successful and was implemented well'. Only one of the district's current four engineers is female, and he suggested that this affects participation from planning and design onwards.

Once project plans have been approved by the district, construction can commence. Since employment in road construction has long been identified by government as a potential arena for women and other disadvantaged groups to earn income, it is particularly important to examine community experiences in this arena. Road work is regularly ongoing in both districts, sometimes instigated by community requests to the district offices for minor road improvements, sometimes more major road works generated from the centre, in which contractors are employed. Projects that originate from community requests mainly require unskilled labour so, in theory, both men and women can participate equally for wages. It is here that we might expect to see benefits for women as they can work close to home. However, for the most part, the work goes to men, with the common justification that women will benefit as much as men in the longer term, once the road is constructed/improved. Some women in Kibaha observed that, a decade or so ago, when basic maintenance work was labourbased (i.e. without machinery), they occasionally obtained work, but opportunities have closed up in recent years

These supervisors do not involve women. There are jobs of uprooting tree stumps and digging trenches but we are told us women are not capable and they take male youth. So for those of us who were able to go to the meetings, we are just informed that the road will be dug in addition to trenches that will be able to provide drinking water. We just see male youth digging the foundation whilst we are capable but are denied employment which we need. 
Another woman added 'they tell us that we women cannot dig ditches, we cannot uproot tree stumps, cannot assemble pipes...'

The view that women only benefit by selling soft drinks or food to the road workers was reiterated by women in both districts and confirmed by their menfolk. One Kibaha man even suggested that women were too busy attending traditional dances, so 'it will be impossible for most of them to attend road construction activities going on at the same time'. Observations from the district's (male) planning officer seem to confirm both the situation and the prejudices that support it

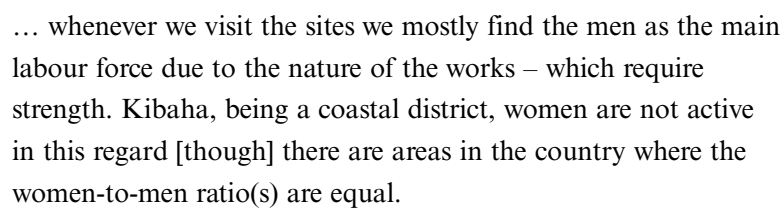

However, the (female) Kwala ward social development officer noted that announcements about potential opportunities are made in the evening - a time at which women are most likely busy at home.

Although there are no cultural practices in the area that constrain women from participating and therefore benefiting from road construction projects, respondents observed that the superior strength of men was a prime reason for limiting road work to male workers in Kilolo district: 'They are all male due to the nature of our work which requires muscles... I opted for men only to avoid running into delays'. The men are recruited through local elders. Some Kilolo women even seem to have imbued male concepts that women are weaker and thus cannot participate (despite their inputs in domestic tasks such as fuelwood carrying and other heavy work). Respondents said: 'We are weak which is recorded in religious books that we are from men and cannot equal them in any way' and 'Men and women are not equal in terms of strength since we get to be pregnant or breastfeeding at times'.

Men in both Kibaha and Kilolo emphasised women's pregnancies, family care duties and the length of the working day on road sites, and even their lack of self-esteem, such that it made sense to give priority to male workers. When asked whether caring tasks could be transferred to men, they simply referred to male inadequacies in this arena. One comment in Kilolo also raised the possibility of men forcibly preventing their women's involvement in road work: 'Women have been threatened to get involved in these tasks. Women are scared to get involved in these things'. Only rarely did men recognise the injustice of the situation: 'Men are born to work, forgetting that even women can work as well; sometimes you would realise that actually women can work better than men'.

Larger district road projects involving contractors are put out to tender and, although contractors are supposedly appointed under the public works department and must follow government procurement guidelines and performance agreements that require them to be 'gender sensitive', in practice they recruit as they wish. According to a key informant with national expertise, in essence there is only ad hoc attention to gender issues in district projects, by contrast with the focus on the needs of women and children' in the planning process of the Village Travel and Transport Programme (VTTP) projects. Male contractors who were interviewed mostly suggested that while women are hardworking and thus invited to participate in projects, it is usually men who come forward. One small road contractor, however, averred that $80-85 \%$ of his labourers were female, with jobs ranging from porterage and cooking to basic storekeeping. He said

For the process of preparing and laying concrete, this job is hard and only men can do it. But in fetching water and sand, this job is carried out by women... Jobs like checking on deliveries, a woman can do this since it involves simply counting the number of trips that the trucks have done in delivering materials like sand and heaps of soil. Men are only picked to do such jobs when there is no woman present. Activities like cooking food on site for the workers, delivering water and sand can be done by women. But situations would vary from one site to another.

He emphasised that the women involved tended to be local women because it would be costly to bring them from his office base and conditions on site might not be suitable for women from elsewhere. He also listed the advantages of employing women over men, including less alcoholism, less tendency to pilfer, greater adherence to instructions and better punctuality.

The most positive sign of change came from Kibaha, where the researchers met the only female contractor active in the two study districts - a woman in her early forties. She runs a small company employing seven other people, four of whom are women (a quantity surveyor, an IT specialist, an office secretary and an office assistant) and three of whom are men (two civil engineers and a quantity surveyor). This remarkable woman (who has a $\mathrm{PhD}$ in finance and also runs a microfinance enterprise lending to women's groups) was much more positive about women's potential to participate in road construction. Citing specific examples, she emphasised

With appropriate sensitisation, women are capable of undertaking construction works just like men! Their role should not be limited to cooking for male labourers... I have not seen even men mix concrete [kumwaga zege] like the women in Dutumi [where she had recently completed work]. I attribute this to sensitisation. I was very happy with these women... I believe women are equally capable [as men].

She pointed out how these women had gained from the experience, learning from the engineering supervisors. Encouragingly, while this contractor has not, as yet, given work 
to any women facing multiple inequalities, she suggested that if they were hardworking, committed and 'explained their case', she would take them on, even giving them priority over others.

The research team was also able to identify and interview a rare woman road technician who supervises under local contractors. She noted that contractors mostly employ casual labour and, on the two projects she is currently working on, there are - as yet - no women workers. However, there had been a woman operating the rolling machine on one of the projects (with both the machine and operator hired from Dar es Salaam). On previous projects she has supervised, women (mostly aged about 25 to 30 ) had been employed mainly for bush clearing and digging terraces, while men mixed and poured concrete and constructed culverts. Again, her view of women workers was very positive. Citing a specific project on which she had worked in the past, she said

They are more patient than men and take instructions kindly. Men are a little chauvinistic, especially if a woman is the one leading a project. They struggle to take instructions. Moreover, men are hardly satisfied with pay. Another difference is the way women handle money; women spend their little income on their families, but most men drink it away... I think with confidence and self-belief, women can achieve much. All they need is capacity building and sensitisation... I find women more trustworthy on construction jobs, better than men.

In Kilolo too, a (male) district officer gave examples where women's contribution was substantial and highly beneficial, referring back to the VTTP projects where road work ensured 'equal gender balance and the coordinator of the project was a woman from the local community'. Other more recent projects were also cited in which there was little male input.

We have projects that have been planned by women and overseen by them... They built a huge bridge across the river which was previously a challenge for women accessing a health facility. The construction was overseen by a woman... From my experience when women do the works themselves, no complaints emerge such as on rain flash water draining into their farms and causing erosion.

These occasional positive examples of women benefitting from road work are encouraging, but the majority of women interviewed are less fortunate. Moreover, vulnerable women in particular, such as widows and the disabled, often appear to be doubly discriminated against in contractor-led programmes. One woman's comment about people living with HIV and AIDS was particularly telling: 'Leaders view it as a humiliation, hence [they] prefer the physically fit in their place'. The degree to which discrimination occurs was evident from interviews with contractors. One observed

We involve people in projects without discriminating against their disability or pre-existing conditions but rather we provide jobs due to ability and strength to do the jobs. As contractors, we are always time bound; we need to deliver on time and work has to be done! We cannot therefore be too benevolent waiting for an incapable widow to finish a job in three days just because she is widow. If this job has to be done in a day, we need someone who can do that in a day. The task cannot delay for such reasons.

Another contractor similarly noted that he is reluctant to employ disadvantaged groups such as older people because they may slow the work down and this will reduce profits. He said 'If a person with disability can deliver only $10 \%$ or only less output for me it's better I hand him 10000 TSH and ask him to go eat [i.e. to go and buy food] and never get involved in my project'.

Some rare, recent positive experiences of vulnerable women obtaining work in road construction were reported in Kilolo, under the Tanzania Social Action Fund (TASAF), the poverty alleviation programme that includes temporary employment opportunities in public works for men and women. The TASAF programme has specifically targeted older people and others on low incomes. The research team met an elderly woman (aged 78) who reported how she had earned a monthly stipend of $30000 \mathrm{TSH}$ (US\$14) for work on local roads, while a 46-year-old widow with a disability who has two children had also benefitted. She had worked for about 4 months under the TASAF programme on a major road upgraded in 2015, having been selected for this through TASAF, saying 'they considered my condition of disability and poverty'. She was assigned to help with taking measurements and digging, for which she had been paid $2300 \mathrm{TSH} / \mathrm{d}$ (US\$1.07), with regular payments every $15 \mathrm{~d}$. However, she said there were no other people with disability employed in the project and emphasised further

\footnotetext{
... except the roads which are maintained locally by the community through TASAF, we the marginalised groups are not involved at all in road projects... we only get to know about them when the authorities come to officially open. We wonder why they call us to the opening ceremonies and why in our community, yet they don't involve us from the beginning.
}

However, in both of these cases the earnings made a crucial contribution to the purchase of household food.

\subsection{National-level perspectives}

Interviews with key actors at national level confirmed the picture from the two study districts. At PO-RALG, it was acknowledged that women's voices may have less priority and their needs are not adequately addressed, this being a factor of budget constraints, such that some positive initiatives to promote women's involvement in the VVTP and local government transport programmes have not been sustainable (notably the training of women contractors, as once occurred in Kibaha district). Thus, it would appear that while there are regulations in place regarding women's employment in the sector and 
directions regarding the promotion of gender equity more broadly, there are insufficient resources available to collect adequate gender-disaggregated data and monitor and enforce the regulations on adherence to guidelines on women's employment on road contracts or other aspects of women's roadrelated benefits. The fact that there is no gender focal point in the headquarters also militates against interventions, as does the small number of women engineers in the roads sector at district level. Given this context for gender as a whole, it is hardly surprising that support for disadvantaged women is extremely limited. All of these issues were confirmed by transport specialists from the donor sector, one of whom observed 'having a policy is one thing, implementation is another and monitoring the implementation is a different issue altogether'. Another pointed to the necessity of much stronger sensitisation to gender issues among village governments, councils and ward executive officers, estimating $80 \%$ in these groups to be 'infected by negative gender stereotypes'. Gender-specialist staff at the MHCGWEC were similarly sceptical about the potential to mainstream gender without adequate resources, noting that what 'most people do to create an impression that yes, gender issues have been mainstreamed [is to...] just add the word women in the [mix and] see how it works!'

\section{Conclusions: review and prospects regarding gender integration in rural transport in Tanzania}

An imbalance in gender power relations lies at the heart of the disappointing story of gender mainstreaming in Tanzania's transport sector presented in this paper. Despite government directives to the contrary, few women have benefitted from employment as road construction workers in the two study districts, except through two national programmes, the VTTP and TASAF (the latter specifically focused on providing temporary work for vulnerable groups).

Community-generated and district-generated projects are particularly open to male capture from the planning stage onwards. Where community consultations do occur, they are focused on gathering male views, with women's voices discounted, and subsequent work opportunities are circulated when and where men will hear of them. Most road contractors are only likely to appoint women as cooks and domestic workers. In Kilolo district, some women seem to have imbued male prejudices to the extent that they do not consider themselves equal to men 'in any way'. All of this means that while many rural men can earn cash from time to time through employment in the road sector, women are mostly kept in the domestic domain, moving water, fuelwood and crops without monetary recompense. Vulnerable women are mostly entirely excluded from employment in the road sector, unless they are fortunate enough to access TASAF work. While it could be argued that most women are time-poor and thus in a weak position to participate in road work, it has to be recognised that this time poverty is a factor of men's reluctance to contribute to tasks that do not produce a tangible cash income. Many women are clearly keen to take on paid work if they can access it.

There are, however, glimmers of hope - notably the stories presented by the female woman road contractor and the female road technician in Kibaha district, both of whom strongly advocate the benefits to be gained through employing women labourers on road works. The fact that they have managed to attain professional positions in the road sector is itself remarkable, given the extent to which prejudice against women prevails in the sector. Sadly, special programmes specifically for training women technicians have stopped in Tanzania, despite the evident, highly significant role they can play in overturning gender biases.

The story is somewhat more encouraging with regard to the wider impacts of road improvement. Most women, including many particularly disadvantaged women, derive benefit, even if only as pedestrians or wheelchair users able to take advantage of a smoother surface, or better travel security when vegetation is cut back. Moreover, for women with the funds and independence to access the expanded transport services that tend to follow on from road improvements, there can be significant benefits - time gained through faster travel, improved access to farms and better markets, sometimes even lower transport costs as services expand. However, even here, men's potential to regulate women's lives is evident: some women in Kilolo district are certainly constrained in their mobility by husbands who fear any expansion of their wives' horizons (viewing this as a potential opportunity for promiscuity). But across both districts, women are still remarkably absent when it comes to operating motorised or even non-motorised transport, whether for their own personal use or as a business enterprise. This is a factor of both women's constrained resources and prevailing cultural mores.

Given the gender differences in mobility opportunities and employment in the transport sector reported in this paper, it is clear that much remains to be done if gender mainstreaming objectives are to be fully integrated in Tanzania's transport sector. Consultations with diverse kinds of female users, female contractors and female employees in the sector are crucial to good design and implementation, yet have rarely been carried out. Mere regulations to support gender-sensitive programmes incorporating consideration of disadvantaged women will never be enough in themselves - without adequate monitoring, these regulations will not be implemented effectively. Resources to ensure such monitoring and the associated implementation of appropriate actions are essential: for women road workers, for instance, the development of a facilitating work environment is crucial, not least crèche facilities and gender-friendly latrines, with their availability built into the performance agreements with contractors. Given financial constraints within government, there seems little potential for the systematic 
collection of the necessary gender-disaggregated data before, during and after transport projects are implemented, unless this is specifically supported by external funding. All of these actions and necessary consequent interventions would benefit from a higher preponderance and visibility of women engineers and planners in the sector, including the placing of knowledgeable gender desk officers in rural areas. A small number of women are in both technical and influential policy roles, but they are massively outnumbered by their male counterparts and have to operate in a wider system that is unconducive to supporting a female-led agenda.

Finally, wider consultations with government at local and national level and with donors will also be essential for improvement in the broader political economy context in which transport projects take place and change is initiated, although bringing both local and national authorities to account is a challenging enterprise (Green, 2014). Delay in the finalisation of the draft National Transport Policy of 2011 (United Republic of Tanzania, 2011) in which gender mainstreaming issues have been addressed is a continuing hindrance to action, for instance, and this requires urgent resolution. The tendency for the transport and other sectors of government to work in silos, without adequate cross-sectoral discussion and action on gender issues, is a further significant constraint. As noted earlier, the arguments of Mbilinyi and Shechambo (2015) regarding the deterioration of conditions for Tanzanian women over the last 30 years are also highly pertinent to such discussions. As they point out, it is vital to understand the wider structures of power within which rural women have to operate - this is a challenge for all sectors and would be more effectively addressed through much stronger cross-sectoral collaboration.

\section{Acknowledgement}

The authors acknowledge the support of the Executive Directors of Kilolo and Kibaha districts, the Assistant District Planning Officer of Kibaha and the Community Development Officer of Kilolo district for allowing this study to take place in their respective districts and for their support in the collection of field data. We also thank the women and men who gave their time to the study by sharing their life stories and experiences, which enriched the findings of the study. This study was conducted under the auspice of the Africa Community Access Partnership (AfCAP) research programme, funded by the UK Aid.

\section{REFERENCES}

Babinard J and Roberts P (2006) Maternal and Child Mortality Development Goals: What Can The Transport Sector Do? World Bank, Washington, DC, USA, Transport paper TP-12. See http://documents.worldbank.org/curated/en/2006/08/7065270/ maternal-child-mortality-development-goals-can-transport-sector (accessed 17/03/2019).

Barwell I and Malmberg-Calvo C (1986) Makete Integrated Transport Project: Preliminary Findings from Village Survey. International Labour Office, Geneva, Switzerland, ILO Rural Transport Paper 4.
Barwell I and Malmberg-Calvo C (1988a) Makete: Integrated Rural Transport Project: The Transport Demands of Rural Households, Findings from a Village-Level Travel Survey. International Labour Office, Geneva, Switzerland, ILO Rural Transport Paper 19.

Barwell I and Malmberg-Calvo C (1988b) Household Travel Demand in Makete District. IT Transport, Ardington, UK, Village level transport survey no. 192.

Bryceson D and Howe J (1993) Rural household transport in Africa: reducing the burden on women? World Development 21(11): 1715-1728.

Ellis A (2007) Gender and Economic Growth in Tanzania: Creating Opportunities for Women. World Bank, Washington, DC, USA.

Fernando P and Porter G (eds) (2002) Balancing the Load: Women, Gender and Transport. Zed Books, London, UK.

Fiander A, Ndahani C, Mmuya K and Vanneste T (2013) Results from 2011 for the transportMYpatient program for overcoming transport costs among women seeking treatment for obstetric fistula in Tanzania. International Journal of Gynecology \& Obstetrics 120(3): 292-295.

Green M (2010) After Ujamaa? Cultures of governance and the representation of power in Tanzania. Social Analysis 541(1): 15-34.

Green M (2014) The Development State: Aid, Culture and Civil Society in Tanzania. James Currey, Oxford, UK.

Haram L (2004) 'Prostitutes' or modern women? Negotiating respectability in Northern Tanzania. In Re-Thinking Sexualities in Africa (Arnfred S (ed.)). Nordic Africa Institute, Uppsala, Sweden, pp. 211-229.

Hine J (2014) Good Policies and Practices on Rural Transport in Africa Planning Infrastructure \& Services. World Bank, Washington, DC, USA, SSATP working paper 100.

Ishengoma CG (2004) Accessibility of resources by gender: the case of Morogoro region in Tanzania. In Gender, Economies, and Entitlement in Africa. Council for the Development of Social Science Research in Africa, Dakar, Senegal, pp. 53-66.

Jennings M (1992) Study on the Constraints to Women's Use of Transport in Makete District, Tanzania. International Labour Office, Geneva, Switzerland

Kabeer N (2014) Gender \& Social Protection Strategies in the Informal Economy. Routledge, Abingdon, UK.

Malmberg-Calvo C (1994a) Case Studies on the Role of Women in Rural Transport: Access of Women to Domestic Facilities. World Bank, Washington, DC, USA, SSATP Working Paper 11.

Malmberg-Calvo C (1994b) Case Study on Intermediate Means of Transport: Bicycles and Rural Women in Uganda. World Bank, Washington, DC, USA, SSATP Working Paper 12.

Mashiri M and Mahapa S (2002) Social exclusion and rural transport: a road improvement project. In Balancing the Load: Women, Gender and Transport (Fernando P and Porter G (eds)). Zed, London, UK, pp. 15-24.

Mbilinyi M and Shechambo G (2015) Transformative feminism in Tanzania: animation and grassroots women's struggles for land and livelihoods. In The Oxford Handbook of Transnational Feminist Movements (Baksh R and Harcourt W (eds)). Oxford University Press, Oxford, UK, pp. 507-530.

Mwankusye J (2002) Do intermediate means of transport reach rural women? In Balancing the Load: Women, Gender and Transport (Fernando P and Porter G (eds)). Zed, London, UK, pp. 37-49.

Ponte S (2002) Farmers and Markets in Tanzania. James Currey, Oxford, UK.

Porter G (2008) Transport planning in sub-Saharan Africa Progress report 2. Putting gender into mobility and transport planning in Africa. Progress in Development Studies 8(3): 281-289. 
Transport

Volume 173 Issue 2
Gendered politics in rural roads:

gender mainstreaming in

Tanzania's transport sector

Mulongo, Porter and Tewodros
Porter G (2011) 'I think a woman who travels a lot is befriending other men and that's why she travels': mobility constraints and their implications for rural women and girl children in sub-Saharan Africa. Gender Place and Culture 18(1): 65-81.

Porter G (2014) Transport services and their impact on poverty and growth in rural sub-Saharan Africa: a review of recent research and future research needs. Transport Reviews 34(1): 25-45.

Porter G (2016) Mobilities in rural Africa: new connections, new challenges. Annals of the American Association of Geographers 106(2): 434-441.

Porter G, Hampshire K, Abane A et al. (2017) Young People's Daily Mobilities in Sub-Saharan Africa: Moving Young Lives. Palgrave MacMillan, London, UK.

Porter G, Hampshire K, Dunn C et al. (2013a) Health impacts of pedestrian headloading: a review of the evidence with particular reference to women and children in sub-Saharan Africa. Social Science \& Medicine 88: 90-97.

Porter G, Tewodros A, Bifandimu F et al. (2013b) Transport and mobility constraints in an aging population: health and livelihood implications in rural Tanzania. Journal of Transport Geography 30: $161-169$.

Starkey P (2011) Sharing the Road: The Impact of Motorcycle Taxis on Socio-economic Development. International Road
Federation, Geneva, Switzerland. See http://www.irfnet.ch/ files-upload/pdf-files/irf_ruraltransport2_r4.pdf (accessed 17/03/2019).

Starkey P, Njenga P, Kemtsop G et al. (2013) Rural Transport Service Indicators: Final Report. International Forum for Rural Transport and Development, London, UK. See https://assets.publishing. service.gov.uk/media/57a08albed $915 \mathrm{~d} 3 \mathrm{cfd} 0005 \mathrm{be} /$ Starkey-etalAfrica-2014-FR-AFCAPgen060-v130908.pdf (accessed $17 / 03 / 2019)$

Turner J, Ntho M and Tanzarn N (2014) Gender-Equitable Rural Transport Planning in Africa: Future Directions. Report to the Africa Community Access Programme, AFCAP, London, UK. United Republic of Tanzania (2003) The Construction Industry Policy. Ministry of Works, Dar es Salaam, Tanzania.

United Republic of Tanzania (2011) National Transport Policy. Ministry of Transport, Dodoma, Tanzania.

Urasa I (1990) Women and Rural Transport: An Assessment of Their Role in Sub-Saharan Africa. International Labour Office, Geneva, Switzerland.

WHO (2015) Global Status Report on Road Safety. WHO,

Geneva, Switzerland. See https://www.who.int/violence_ injury_prevention/road_safety_status/2015/en/ (accessed 04/04/2019). 